\title{
Behavioral modelling of subjects in legal cases- games with imperfect rationality
}

\author{
Valentina Sergeevna Nikitina* \\ RUDN University, Institute of Law, Department of Theory of Law and State, Moscow, Russia
}

\begin{abstract}
Game theory, applied in various fields, including in law, studies conflict game models and searches for their formatted solutions, makes it possible to solve many tasks and problems, predict the behaviour of subjects in various situations, thereby explaining the behavior logic of the individuals in conflict of interests. However, human behavior is not always rational (reasonable), moreover, it can be difficult to predict which strategy the player will choose when making his move in the game. In this regard, it is advisable to consider rational behavior as an accepted and reasonable behavior of game participants and irrational behavior as deviant, unpredictable behavior of players, which relies on the internal regulation of a person (beliefs, intuition, creativity, feelings, emotions, etc.) and which studies one of the developing directions of game theory in modern science - evolutionary game theory. The study aims to determine the types of irrational behavior of players, which puts other players in a difficult position and precludes from determining each other's optimal strategies for mutual benefit and stability, using the example of legal incidents modeling through games with imperfect rationality. The authors believe, that to achieve this goal using the methods of analysis and modeling, the imperfections of rationality can be considered and studied, the types of irrational behavior of players can be defined using the games with imperfect calculation of the game, imperfect information and changes in goals during the game (with a multipersonal representation of the game) and a complete absence of rationality.
\end{abstract}

Keywords: game theory, evolutionary game theory, rational subject, irrational behavior, legal incidents

\section{Introduction}

The founders of game theory Neumann and Morgenstern, set the task of creating a theory that would point the subject to a rational way of behavior. Game theory is defined as a method for studying mathematical models of conflict situations and cooperation between rational decision-makers. The authors defined "the criterion of rationality, according to which all strategies are rational, whose outcomes are the best of the worst provided to the player by his opponent, and indicated that if each player is rational, then the solution to the conflict will be stable" [1].

\footnotetext{
*Corresponding author: nikitina-vs@,rudn.ru
} 
However, rationality may not so much be an implied "ideal" as an unrealistic fantasy in human decision-making behavior. For example, "buying a lottery ticket is considered rational behavior even if the person knows that the expectation of his winnings is negative. But if a person constantly buys lottery tickets, where the chances of winning are $1 / 20000$, and not tickets of the same cost with the chances of winning 1/10000, then this behavior can hardly be called rational" [2].

The rational subject is faced with a simplified world and easier decision making. However, this simplicity is both an advantage and a potential disadvantage, since the actual human behavior is more complex. Therefore, game theory is making progress and developing in various directions. When creating game theory, the indication of the rational behavior of players in any situation was the main importance, later the active study of the evolutionary theory of games began with consideration of the irrationality of the players (behavior, deviating from the recognized rationality).

The research background is based on the fact that the behavior of players during the game is not always rational and reasonable, which leads to unpredictability of the choice of its further strategies when making decisions and puts other players in a difficult position, precluding from determination of each other's optimal strategies for mutual benefit and stability. Modern science distinguishes one of the directions of game theory - evolutionary game theory, which studies the irrational behavior, that is, deviant behavior of the players, which is influenced by internal beliefs, emotions, feelings, etc. [3-5].

Research hypothesis: the player's behavior in modelled legal situations can be both rational and reasonable, and irrational.

The purpose of the study is to determine the types of irrational behavior of players by the example of modeling legal incidents using games with imperfect rationality and to substantiate the need to consider both rational and irrational behavior when players choose their strategies.

\section{Methods}

Upon review and analysis of foreign and domestic research, it can be concluded that the theory of games, applied in various fields, including in law, considers the behavioral logic of individuals in a conflict, and indicates that the behavior of subjects when making decisions can be both rational and irrational. Modeling legal situations using games with imperfect rationality makes it possible to consider the irrational behavior of subjects using real, practical examples.

\section{Results}

The results demonstrating the types of subjects' behavior and its influence on the outcome of the game are presented in a diagram that reflects the specifics of rational behavior, irrational behavior and its practical implementation on the example of games with imperfect rationality. 

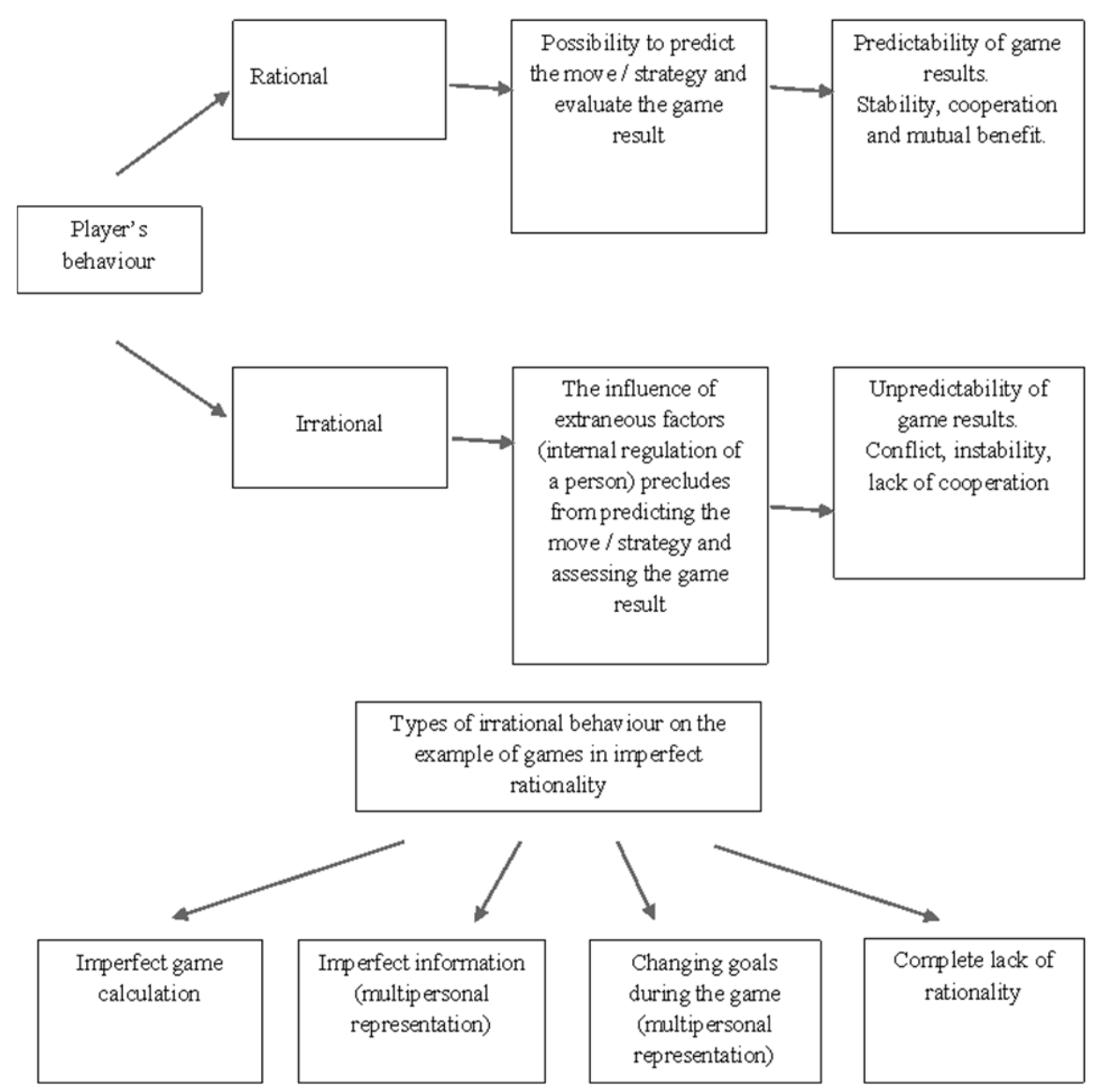

Fig. 1. The types of subjects' behaviour.

\section{Discussion}

The goal of game theory is to allow players to predict game outcomes using interactive models in which the actions and decisions of one player depend on the actions and decisions of another player, as well as their rational or irrational behavior $[6,7]$. Rational behavior means that the decision-making behavior of each individual would be consistent with maximizing subjective expected utility when the decisions of other individuals were known. Generally, it is assumed that the participants try to do their best, given their goals and information. The goal should not be selfish, and the information should be incomplete, but certain consistency requirements should be imposed on preferences so that the player knows how to predict the behavior of others. Therefore, if the players act rationally (equally reasonably), then there is an equilibrium position that will determine for each player the equilibrium average payoff, which is realized if everyone behaves reasonably, that is, adhere to optimal strategies. However, if one of the players behaves irrationally and adopts a different, non-optimal strategy, then his average payoff will accordingly decrease or increase and his strategy will be unpredictable for the other player [8-10]. 
In fact, assumptions of rationality are often violated, but serve as a useful guide. For example, when decision-makers are rational and reasonable, the existing significant role of the institutions of law and the laws is likely to remain, even if the actors act irrationally. Moreover, special provisions for persons whose behavior is not classified as rational are often included in the law. For example, it matters in criminal law whether the crime was committed with intent or whether the offender was of sound mind at the time of the crime, while the contract law distinguishes special groups of persons unable to enter into certain types of contracts [11].

On the one hand, law is something rational since it consists of legal norms are a rational product, as the establishment of a general obligation. On the other hand, law is not only a set of norms, but also a life phenomenon, a set of legal relations and individual rights and obligations, a set of life factors of legal significance, which are often irrational, since they are individual, unique and peculiar. When law is studied not only as a system of general provisions and concepts of subjective law, but also in all its manifestations, the irrational side of law becomes noticeable [12].

True irrationality can have different reasons, so it seems possible to simulate legal life situations using the example of games with imperfect game calculation, imperfect information, changing goals during the game and a complete lack of rationality.

A situation with an imperfect game calculation is possible when a player with the made move tries to signal to his own advantage his hypotheses (true or bluff), relative to another player. The use of bluffing strategies at auctions is considered one of the most frequent violations of antitrust laws, causing significant damage to the state. The essence of such strategies is that one player, unlike others, offers an ultra-high bid, which leads to the fact that the size of the fees of other participants ceases to matter in determining the winner. Thus, bluff is the appointment of one of the players of an ultra-high bid [13]. Thus, players who do not imply that a bluff is being played against them (dishonest trick) declare a bid that, in their opinion, corresponds to the real value of the auctioned item, and act rationally, while players using the maximum bid (bluffing strategies) act irrationally, violating the normal applicable reasonable behavior in the conduct of auctions, in which the players would be on an equal footing in making the choice of strategies in the game. Thus, the irrational player is confident in his victory and hopes for a bluff, which is implemented not only by his own efforts, but also by the "ignorance" of other participants [3, 14].

A game with imperfect information, which indicates an irrational behavior of the subject, can be represented by a multipersonal representation of the game, which consists in the fact that the same player can be represented by different players in different situations, in particular, after the player has not provided (hid) important information [15]. Let us model a legal situation when a person, having information about circumstances that pose a threat to the life or health of people, considers it necessary to transfer information to the law enforcement agencies, while modeling in advance what will happen if he hides such information. Accordingly, he projects himself in the image of another player, whose move is to conceal information, for which criminal liability is provided (Article 237 of the Criminal Code of the Russian Federation) [16]. This image gives no possibility to determine the next move of the player, since it is unknown whether the player wants to convey information or hopes that no one will find out about this and hide the information. Moreover, with the help of the multipersonal representation of the game, it is possible to simulate such a situation when the irrationality of the players is to change goals during the game. An example is a situation often considered in judicial practice, which is associated with the activities of construction companies in the implementation of urban planning activities and the operation of various objects. Carrying out such activities, construction companies aim to comply with environmental requirements in order to avoid administrative (Article 8.1. Administrative Code of the Russian Federation) [17] and criminal (Article 246 
of the Criminal Code of the Russian Federation) [16] liability. However, there can always be a situation when the implementation of further construction can cause environmental damage and the company is faced with the choice to abandon actions that cause damage to the environment by not fulfilling its obligations (for example, by failing to hand over the construction object on time), or to violate the environmental requirements to a certain extent, thereby becoming legally liable, but to receive its own benefit. Based on this, the goals of the company can change in the course of the game, when it faces the problem of full or partial compliance, or non-compliance with environmental requirements in general. Most likely, the company would prefer to minimize damage, both to itself and to the environment, and would choose minimal damage and administrative liability, but there is a risk that such activities could get out of control and lead to criminal liability. In this case, the company's behavior becomes unpredictable and irrational, since it is unknown what strategy it will choose and what internal beliefs it will rely on in this choice.

Situations without rationality are also possible, when the type of behavior is difficult to calculate and optimize. For example, two legal entities, representing a fiction, behind which there are many people with different opinions, when concluding contracts, choose an aggressive or peaceful policy of their activities. Two "peaceful" legal entities enter into a contract on terms favorable to both, and two "aggressive" ones collide, maximizing their own interests, reputation and benefits. If one is "peaceful" and the other is "aggressive", then, accordingly, "peaceful" will yield to the stubbornness of the "aggressive". The politics of such actors cannot be precisely defined, since they can be led by many people with different opinions, which also speaks of irrational behavior.

\section{Conclusion}

Such examples prove that the behavior of subjects in various legal situations can be both rational and irrational. Reasonable player behavior is not always possible to predict and evaluate using basic, general provisions of game theory. Internal beliefs, emotions, feelings, intuition, creative thinking, inspiration, creativity, morality as the basis of a person's internal regulation, which cannot always be replaced by "cold rationalism", withstand mathematical and game modeling [5].

\section{References}

1. J. von Neumann, O. Morgenstern, Teoriya igr i ekonomicheskoe povedenie [Game theory and economic behavior] (Nauka, Moscow, 1970)

2. N. Saperov, Mikroekonomika [Microeconomics]. Accessed on: July 06, 2021. [Online]. Available: https://n2tutor.ru/materials/handbook/

3. P.L. Lorentziadis, Europ. J. Oper. Res. 248(2), 347-371 (2016). https://doi.org/10.1016/j.ejor.2015.08.012

4. G. Liu, B. Xiao, D. Li, Game-theory based driving decision algorithm for intersection scenarios considering driver irrationality, in Proc. 4th CAA Int. Conf. on Vehicular Control and Intelligence, CVCI 2020. 18 December 2020. https://doi.org/10.1109/CVCI51460.2020.9338515

5. K. Binmore, Teoriya igr. Oche kratkoe vvedenie [Game theory. A very short introduction] (Delo, Moscow, 2017)

6. D.G. Baird, R.H. Gertner, R.C. Picker, Michigan L Rev 94(6), 1839-1882 (1996)

7. X. Hu, M. Wu, Int. J. Mod. Phys. 32(5), 2150066 (2021).

https://doi.org/10.1142/S0129183121500662 
8. I.P.L. Pэng, The Bell J. Econ. 14(2), 539-550 (1983)

9. J. Thoma, Erkenntnis, 85, 1219-1240 (2020). https://doi.org/10.1007/s10670-0180074-9

10. G. Muthusamy, K.T.G. Cheng, Europ. J. Molec. Clin. Med. 7(3), 240-250 (2020)

11. P.H. Huang, Jurimetrics, 36(1), 99-114 (1995)

12. B.A. Kistyakovsky, Filosofiya i sotsiologiya prava [Philosophy and sociology of law] (Russian Christian Humanitarian Institute, Saint Petersburg, 1998)

13. A.F. Rogachev, A.A. Marchenko, Bus. Edu. Law. Bul. Volgograd Instit. and Bus. 1(18), 182-186 (2012)

14. M.A. Javarone, J. Stat. Mech.: Theory and Exper. 2015, P03018 (2015). https://doi.org/10.1088/1742-5468/2015/03/P03018

15. A.V. Zakharov, Teoriya igr v obshchestvennykh naukakh [Game theory in the social sciences] (HSE Publishing House, Moscow, 2019)

16. "Ugolovnyi kodeks Rossiiskoi Federatsii" ot 13.06.1996 No. 63-FZ (red. ot 24.02.2021) ["The Criminal Code of the Russian Federation" dated 13.06.1996 No. 63FZ (as amended on 24.02.2021)]. Accessed on: July 06, 2021. [Online]. Available: http://www.consultant.ru/document/cons_doc_LAW_10699/

17. "Kodeks Rossiiskoi Federatsii ob administrativnykh pravonarusheniyakh" ot 30.12.2001 No. 195-FZ (red. ot 24.02.2021) (s izm. i dop., vstup. v silu s 07.03.2021) ["The Code of the Russian Federation on Administrative Offenses" dated 30.12.2001 No. 195-FZ (as amended on 24.02.2021) (as amended and supplemented, entered into force on 07.03.2021)]. Accessed on: July 06, 2021. [Online]. Available: http://www.consultant.ru/document/cons_doc_LAW_34661/ 